\title{
Discussion on the Medical English Teaching Based on Flipped Classroom
}

\author{
Lei Liu \\ Foreign Language Department in Qiqihar Medical University, Qiqihar161006, Heilongjiang, china \\ 84056867@qq.com
}

\section{Keywords: Flipped classroom; Medical English; College English teaching}

\begin{abstract}
From the view of the essence and characteristics of flipped classroom, this paper discussed the prospect and possible problems of applying the flipped classroom to medical English teaching and put forward a feasible solution from the actual situation in order to provide the reference for the application of the flipped classroom in medical English teaching.
\end{abstract}

\section{Introduction}

With the gradual deepening of the globalization of economy and the internationalization of Education, the demand of cultivating the application-oriented talents with international vision and intercultural communication ability poses a severe challenge for the reform of college English teaching in medical college. In order to understand the dynamic state of the latest medical frontier, the ability to read English journal literature should be required. Excellent papers of clinical and other medical specialities also should be published in international journals in English. Participation in international academic exchanges is also inseparable from good English skills. English communication between doctors and patients should also be improved. How to improve English proficiency and comprehensive ability of medical students has become an urgent problem to be solved in college English teaching.

Flipped classroom is a new type of teaching mode. Through the method of "learning by watching the video before class and the internalization of knowledge in class", it flipped classroom learning activities and extracurricular activities and realized the reform of traditional single classroom teaching mode. With the further integration of the development of network technology and the disciplines and specialty, flipped classroom has gradually become a typical example to promote teaching reform in schools. As a medical college, it is beneficial to promote the effect of classroom teaching and promote the process of college English teaching reform by building college English mixed teaching model which is based on flipped classroom and conforms to its own characteristics.

\section{The Essence and Characteristics of Flipped Classroom}

In essence, flipped classroom is to free teachers from the role of simple knowledge initiator and let them have time and energy to solve practical problems to improve the efficiency of teaching. For students, flipped classroom is to cultivate students' learning enthusiasm and initiative, let them overcome inertia and increase their learning motivation. Also flipped classroom can make them study independently, so as to really learn knowledge and improve their creative ability and comprehen sive application ability.

As a reform of the teaching model, the flipped classroom has the following characteristics. The first one is the individualized learning. In flipped classroom teaching mode, the process of imparting knowledge is transferred from the teacher's teaching in class to the students' independent study after class. Students can control their learning time, learning place, learning content and the amount of learning according to their learning style and learning characteristics. Flipped classroom teaches students in accordance of their aptitude and makes up for the individual differences of students. The second one is the deep cooperative learning. On the basis of understanding, learners critically accept new information, integrate it into the existing cognitive structure and transfer the existing knowledge to the new situation[1]. In flipped classroom teaching mode, the time for 
students' interaction and the interaction between teachers and students in class is greatly increased. Students and teachers can carry out a deep discussion, thus students' critical thinking ability and innovation ability can be enhanced. The third one is the seamless mobile learning. It refers to a learning method which combines formal and informal learning that students can study at anytime and any place[2]. Flipped classroom can upload the main content of learning to the network learning platform in the form of multimedia and preserve it permanently. In that way, students can choose a convenient time and place to study. The fourth one is the initiative inquiring learning. Learning is a process of building knowledge actively rather than passively absorbing it. Students study the materials autonomously before class, actively learn knowledge and actively participate in and discuss relevant topics in class, thus their independent learning ability can be enhanced.

\section{The Current Situation of Medical English Teaching}

ESP (English for Special Purposes) focuses on the discourse genre of specific subjects (such as medicine, law, engineering, etc) and the ability to communicate in English in workplace[3]. ESP is not a simple language learning. The purpose of it is not to learn English but to integrate language knowledge with professional knowledge. Through the learning of English, the understanding and mastery of professional knowledge can be enhanced so as to serve professional learning. It embodies the instrumentality of the English language.

In the past ten years, ESP has gradually had an impact in the academic circle and is regarded as an inevitable way to achieve the ultimate goal of college English teaching. More and more scholars begin to try this new teaching idea and have achieved initial success. In order to cultivate excellent and applied medical students in line with international standards, medical colleges and universities have begun the practice of medical academic English teaching. The existing problems are discussed as follows: The first one is that it doesn't help much in the learning of the professional knowledge. In order to avoid the difficult and obscure problems of the old medical English textbooks, now many medical colleges and universities choose simple and understandable popular English textbooks. Many students have mastered the professional knowledge of their textbooks, so they focus more on some complex professional English vocabularies. But most English teachers know little professional knowledge about medical English, can't analyze the medical subject in class deeply and can't help students comprehend by analogy. Therefore, they didn't help much in the learning of the professional knowledge of students and even weaken the learning enthusiasm of students. The second one is that the classroom learning is boring. Due to the limited medical knowledge, English teachers can't expand the content of the textbook and the teaching is very superficial. The almost abandoned traditional teaching mode has returned to the college English teaching classroom. In fact, students feel boring in class and teachers are also boring. The enthusiasm of students and teachers is also affected. It virtually creates resistance to the development of ESP Teaching.

\section{The Prospect of the "Flipped Classroom" of Medical English Teaching}

The Individualized Learning of Flipped Classroom is Conductive to Enhancing the Enthusiasm of Medical Students for Learning Medical English. Cultivating students' learning interest is an important part of medical English teaching. The traditional English classroom teaching can not meet the needs of students with good English proficiency and the enthusiasm of learning English of students with poor English proficiency may be struck. This situation has affected the effectiveness of classroom teaching. In flipped classroom teaching mode, students can study according to their own situation and adjust the learning rhythm independently before class. When they return to the classroom teaching, students stand on the similar starting line. And then through the personalized guidance of teachers in class, the personalized teaching is achieved. The individual difference of students can be taken into account and the overall English learning effect of students can be improved. 
The Deep Cooperative Learning of Flipped Classroom is Conductive to Cultivating the English Application Ability, Critical Thinking and Team Work Spirit of Medical Students. As a branch of ESP, the applicability and practicability are the core of medical English. In the flipped classroom teaching mode, students have completed the preliminary knowledge study before class, so they have enough time to do various interactive activities in class, thus they can effectively improve their medical English communication and application ability. At the same time, teachers can get feedback from students timely by interacting with students, correct students' mistakes in real time and provide real-time guidance for students' learning. Therefore, the learning effect of students can be improved significantly. In addition, students can make a thoughtful discussion with teachers and other students in the classroom. In the process of discussion, students can understand knowledge deeply and also the critical thinking, innovative thinking and team work spirit of students can be cultivated. The classroom is no longer an one-way instillation of knowledge, but the enlightenment and communication of the thinking of teachers and students.

The Seamless Mobile Learning of Flipped Classroom is Conductive to the Flexible and Autonomous Learning of Medical Students. With the support of the network information technology, flipped classroom requires students to study the original class contents after class and efficiently provides rich learning resources for students by using network. Students can learn according to their own time, study the teaching materials in the online teaching platform independently and complete the online test to make seamless and mobile learning in order to complete the learning and internalization of curriculum. Flipped classroom changes the situation that students don't study after class and meanwhile it solves the problem of the shortage of medical English courses. It releases lots of classroom teaching time, so that the classroom time can be used to discuss the key points and difficulties in the learning so as to make full use of the limited time.

The Initiative Inquiring Learning of Flipped Classroom is Conductive to Cultivating the Autonomous Learning Ability of Medical Students. Flipped classroom is a beneficial trial to cultivate the autonomous learning ability of students in the network information times. It changes the traditional teaching mode and takes learners as the center. In the course of learning after class, students are the masters of learning. In class communication links, due to the preparation of knowledge before class, students participate in discussion actively and the learning initiative of students is also greatly enhanced. Teachers can make face-to-face and one-to-one communication with students. They can put the problems together and discuss them and then explain and demonstrate, which significantly improves the efficiency of classroom learning. Students also develop autonomous learning ability and self-control ability in autonomous inquiry learning.

\section{The Problems and Solutions under the Teaching Model of "Flipped Classroom" of Medical English}

Flipped classroom teaching mode will face some problems in the implementation process. As a new mode of flipping the order of traditional teaching mode, it will bring some challenges and problems to students and teachers, especially in the adaption phase.

From the perspective of students, flipped classroom mode requires students to complete the relevant learning contents before class instead of studying main learning contents in class as traditional teaching did, therefore students will contradict it and can't adapt it. They may need to invest more time and energy before class. Therefore, the conflict in the initial phase may show that students didn't prepare for the classroom discussion and can't participate it actively. Therefore, teachers can give students a short test at the beginning of the class to test whether the students have prepared the learning contents according to the requirements before class or they can design the corresponding assignment based on video, reading and other materials to ensure that students have prepared the learning contents before class. Secondly, medical English textbooks involve a large number of medical vocabulary and most of them are obscure, which will bring some obstacles to students' learning before class. Therefore, teachers can provide high-quality video before class to instruct students. And relative to the text materials, students prefer video mode. In addition, the new teaching mode puts the knowledge teaching part before class, which has a certain influence on the 
arrangement of students' study time and requires students to spend more time preparing before class. Therefore, the school can provide information technology support, such as providing a unified data upload and download platform to facilitate the communication between teachers and students.

From the perspective of teachers, the making of high-quality videos and micro courses has put forward high requirements for teachers. Teachers need to learn new production software and they need to invest more time and effort to the teaching. Schools can offer some learning courses for teachers to improve their teaching preparation efficiency. At the same time, the mode of flipped classroom is not single, which requires teachers to choose the proper teaching mode in the course of combining the flipped classroom with the medical English teaching and constantly perfect the teaching materials before class. The formation of the teacher data network can allow different teachers to share their videos and materials on the platform. In that way, teachers can discuss with each other periodically and also it can provide more time for teachers to design classroom activities.

\section{Conclusion}

According to the relevant regulations of the "college English curriculum requirements" which is issued by the Department of Higher Education of the Ministry of Education in 2007, "colleges and universities should make full use of modern information technology and adopt the English teaching mode which is based on the computer and classroom to improve the single teaching mode which takes the teachers' teaching as the main. The new teaching mode should be established with the support of modern information technology, especially the network technology, which makes the teaching and learning of English can't be limited by time and place to a certain extent and develop toward the direction of individuation and autonomous learning[4]." Flipped classroom is a new teaching mode based on modern network information technology, which combines the advantages of the individualized learning, deep cooperative learning, seamless mobile learning and independent inquiry learning. Applying flipped classroom to medical English teaching will be conductive to improving the learning initiative, English application ability and autonomous learning ability of medical students and cultivating the critical thinking and teamwork spirit of medical students. At the same time, we can notice the practical problems faced in the implementation of flipped classroom teaching, such as the construction of software and hardware, the change of teachers and students' ideas, the cultivation of information literacy and so on. In the initial exploration stage, we can design part of the existing curriculum to the flipped classroom and constantly sum up experience in practice in order to better promote the optimization reform of medical English teaching.

\section{Acknowledgements}

Project source: Teaching Reform Project for English Special of Heilongjiang Higher Education in 2015.

Project name: the Teaching Research of EMP Based on the Professional Requirements of Medical University Under the Circumstance of Flipped Classroom model.

Project number: 0315008

\section{References}

[1] Kimberly Hoffman, Michael Hosokawa, Robert Blake Jr, etc: Problem-based Learning Outcomes: Ten Years of Experience at the University of Missouri--- Columbia School of Medicine [J], Academic Medicine, 2006,81 (7): 617-625.

[2] J.R.Zhang: Strategies Regarding Some Problems in Classroom Teaching of Preventive Medicine[J], China Higher Education, 2008,(8):62-62.(In Chinese)

[3] J.G.Cai: English for Academic Purposes and Quality Foreign Language Education[J], Computer-assisted Foreign Language Education, 2014(157): 3-8.(In Chinese)

[4] Higher Education Division of the Ministry of Education: The College English Curriculum 
Teaching Requirement[M], Shanghai Foreign Language Education Press, 2007.(In Chinese)

[5] Y.J.Liu: Innovative Talent Cultivation in the Context of the Medical English Teaching Reform[J], Northwest Medical Education, 2012, 20 (6): 1220-1223.(In Chinese)

[6] C.J.Wang, W.P.Hu and W.D.Li: "Flipped" Classroom: Technology Promotes Teaching[J], E-education Research, 2013,(8):73-78.(In Chinese)

[7] C.Y.He, Y.F.Ou and Q.Cao: Inspiration of USA Universities' Inverted Classroom Teaching Model[J], Research in Higher Education of Engineering, 2014, (2): 148-151.(In Chinese)

[8] Q.Zhang: Discussion on the Current Situation and Reform Thinking of Medical English Teaching Model[J]. Gansu Science and Technology, 2010,26 (23): 181-182.(In Chinese)

[9] X.L.Zhao: Advancement and Limitation of Flipped Teaching[J], Journal of The Chinese Society of Education, 2013: 65-68.(In Chinese)

[10] Millard E. 5 Reasons FLIPPED Classrooms Work[J], University Business, 2012. 